\title{
К ВОПРОСУ АКТУАЛЬНОСТИ РАБОТ ПО УСТАНОВЛЕНИЮ ГРАНИЦ ЗОН ЗАТОПЛЕНИЯ И ПОДТОПЛЕНИЯ (НА ПРИМЕРЕ ТЕРРИТОРИИ ГОРОДА НОВОСИБИРСКА)
}

\section{Алексей Викторович Дубровский}

Сибирский государственный университет геосистем и технологий, 630108, Россия, г. Новосибирск, ул. Плахотного, 10, кандидат технических наук, зав. кафедрой кадастра и территориального планирования, тел. (383)361-01-09, e-mail: avd5@ssga.ru

\section{Елена Андреевна Скоринская}

Верхне-Обское бассейновое водное управление, 630087, Россия, г. Новосибирск, ул. НемировичаДанченко, 167, ведущий специалист-эксперт, тел. (383)314-89-15, e-mail: lenavoro95@mail.ru

В Российской Федерации только начинаются работы по установлению зон затопления и подтопления. Законодательно установлено внесение сведений о границах этих зон в единый государственный реестр недвижимости. Однако, при этом существует ряд нормативно-правовых и технологических вопросов, которые не решены и работы по установлению зон затопления и подтопления не выполнены в полном объеме. В статье дано описание основных руководящих нормативных документов, а также показаны новшества, которые внесли данные законы для усовершенствования процедуры установления зон затопления и подтопления.

Ключевые слова: объекты недвижимости, геоинформационные системы, кадастровые работы, зоны затопления, зоны подтопления, гидротехническое сооружение, обеспеченность паводка, чрезвычайная ситуация, градостроительная деятельность

\section{TO THE QUESTION OF THE RELEVANCE OF WORK ON ESTABLISHING THE BOUNDARIES OF ZONES OF FLOODING AND FLOODING (FOR EXAMPLE, THE CITY OF NOVOSIBIRSK)}

\section{Alexey V. Dubrovsky}

Siberian State University of Geosystems and Technologies, 10, Plakhotnogo St., Novosibirsk, 630108, Russia, Ph. D., Head of the Cadastre and Territorial Planning Department, phone: (383)361-01-09, e-mail: avd5@ssga.ru

\section{Elena A. Skorinskaya}

Upper Ob Basin Water Management, 167, Nemirovich-Danchenko St., Novosibirsk, 630087, Russia, Leading Specialist Expert, phone: (383)314-89-15, e-mail: lenavoro95@mail.ru

In the Russian Federation, work is just beginning to establish flooding and flooding zones. The legislation establishes the entry of information about the boundaries of these zones in the unified state register of real estate. However, at the same time, there are a number of regulatory and technological issues that have not been resolved and work on the establishment of flooding and flooding zones has not been fully implemented. The article describes the main governing regulatory documents, as well as shows the innovations that these laws have introduced to improve the procedure for establishing flooding and flooding zones.

Keywords: negative impact of water, flood zones, flooding, hydraulic structure, waterworks, flood security 
Люди ежегодно подвергались негативному влиянию вод в периоды весенних и дождевых паводков, так как старались селиться вблизи водных артерий. Упоминания об этом можно найти в разных источниках, но 21 веке последствия от наводнений приобретают катастрофический по последствиям и разрушениям характер.

При затоплении резко ухудшаются свойства земельных участков, а находящиеся на них объекты недвижимости теряют часть рыночной стоимости вплоть до полного обесценивания объекта. Почва теряет часть плодородных свойств, кроме того в результате деятельности водной среды может появиться загрязнение земель, как продуктами разрушения конструктивных элементов объектов недвижимости, различным мусором, в том числе твердыми коммунальными отходами.

Например, в 2019 г в результате выпадения обильных осадков и прохождения паводка в Иркутской области в притоках реки Ангара уровень воды поднялся выше критических на р. Ия до 14 м, при критическом 700 см, на реке Ока до 10 м, при критическом 470 см, на реках Уда, Белая, на 2,5-3 м выше критических, только в первые дни в 28 населённых пунктов, 5 муниципальных районов (Нижнеудинском, Тайшетском, Тулунском, Чунском, Зиминском) было подтоплено 3735 жилых домов и 3747 приусадебных участков с населением 4177 человек, 18 социально-значимых объектов. Пострадали 102 человека. Были повреждены 13 автомобильных мостов, подтоплены и частично разрушены участки автомобильных дорог регионального и федерального значения, рис. 1 [1].

В настоящее время ликвидация нанесенного ущерба объектам недвижимости и инфраструктуры продолжается. С 2019 года на всей территории Иркутской области по указу Губернатора от 27.06.2019 № 134 в 42 муниципальных образований действует режим чрезвычайной ситуации [2]. Строительство только объектов инженерной защиты от наводнений и мероприятия по ликвидации последствий в пострадавших районах, предусмотренные государственной программой до 2023 года, реализуемой за счет средств федерального бюджета и консолидированного бюджета Иркутской области по предварительным расчетам, составит 6,8 млрд руб. Только в городе Тулуне к 2020 году завершено строительство всего 136 зданий и 73 домов из запланированных 840 зданий и 244 домов [2-4].

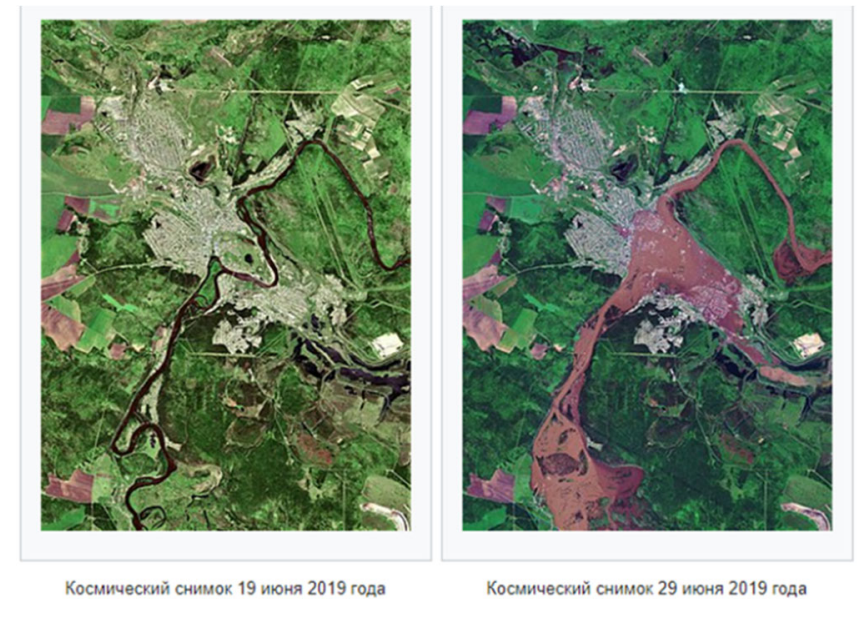

Рис.1. Сравнение данных дистанционного зондирования территории г. Тулун до и после катастрофического паводка 
Для установления причин, по которым современному обществу с каждым годом приходится терпеть все большие человеческие и материальные жертвы нужно обратиться к истории. Земли, прилегающие к водным объектам с древних времен, имели огромную ценность из-за отсутствия централизованных систем водоснабжения и водоотведения. Помимо удовлетворения минимальных потребностей человека в воде, водоемы использовались для водопоя животных, рыбалки, полива. В советской России жилищное строительство являлось важнейшей отраслью народного хозяйства. Приоритетной задачей государства было обеспечение в короткие сроки граждан жильем. При этом вопросам регулирования градостроительной деятельности не уделялась должного внимания. Отсутствие такой необходимости можно объяснить и тем, что земли принадлежали государству, большая часть возводимого жилья предполагалась для временного использования. Лишь с восстановлением института частной собственности вопросы градостроительства и выбора безопасных экологически комфортных условий для рассположения объектов недвижимости приобрели особую актуальность. В 1992 г был принят первый Федеральный закон о «Регулировании градостроительства в Российской Федерации», а впоследствии в 1998 году первый Градостроительный Кодекс [5].

Долгое время строительство и размещение объектов недвижимости вблизи водных объектов основывалось на главном принципе - соблюдения режима водоохранных зон, прибрежных защитных полос (В3, ПЗП) который периодически подвергался изменениям в сторону «упрощения» самого режима, требований к порядку определения, а также уменьшения размера границ В3 и ПЗП. Сдерживающим механизмом размещения объектов вблизи водоемов служит береговая полоса водного объекта, которая согласно действующему законодательству является территорией общего пользования.

Так как большинство зон с особыми условиями использования территорий (ЗОУИТ) считаются установлеными и отображаются на публичной кадастровой карте, схемах территориального планирования, градостроительного зонирования со дня внесение в ЕГРН при проведении оценочных работ по определению кадастровой и рыночной стоимости объектов недвижимости не учитывается факт нахождения объекта в ЗОУИТ, а также ограничений на его использование, что повышает спрос на территории вблизи водных объектов, но не исключает рисков [6]. Согласно отчету компании «Авито» в 2019 спрос на недвижимость вблизи водоемов в среднем по регионам вырос на $38 \%$, а стоимость, например, в Ленинградской области повысилась на 9\%, в Новосибирской области стоимость увеличилась на $8,7 \%$, в Ставропольском крае на 10,6\% [7].

Еще одной причиной осложнения прохождения паводков и наводнений являются гидродинамические аварии. Это аварии, связанные с выходом из строя гидротехнических сооружений (ГТС). Наибольшую опасность представляют водонапорные ГТС, представленные плотинами малых и средних водохранилищ. Большинство из малых и средних водохранилищ было построено в 60-70 годы и часть их имеет статус бесхозяйных ГТС. Это ГТС, сведения о которых не вносились в Российский регистр гидротехнических сооружений, не поставлены на 
учет как объекты недвижимости. Как правило, к таким бесхозяйным ГТС, представляющим потенциальную опасность относятся сельскохозяйственные пруды, используемые для местных нужд, не имеющие проектной документации $[6,8]$. ГТС которые используются для энергетики, промышленности, транспорта к бесхозяйным относятся редко. Они подлежат строгому надзору различных органов: Ростехнадзора, МЧС, Минстроя, Росприроднадзора, Минприроды и ряда других. Такие ГТС имеют декларации безопасности, паспорта ГТС, правила использования и другие документы. Но аварии на них случаются нередко, а масштабы значительны. Причинами таких аварий являются ошибки в эксплуатации, несоблюдение установленных норм и правил, износ ГТС, ошибки при проектировании.

Например, в результате паводков в Иркутской области прорвало защитную дамбу на реке Ия в городе Тулун, а затем под напором воды не выдержала дамба на реке Ока, что значительно осложнило прохождение дождевого паводка в 2019 году и привело к разрушительным последствиям, рисунок. В результате наводнения в погибло 25 человек, без вести пропавшими числятся 11. Всего в Тулунском, Тайшетском, Нижнеудинском и Чунском районах было затоплено почти 11 тысяч домов, в которых живут 34,2 тысячи человек, 8 тысяч из них - дети. Число нуждающихся в материальной помощи достигло почти 38 тысяч человек, рис. $2[3,4]$.

Последствия прохождение крупных паводков за последние 20 лет в СФО на таких реках как Кондома в Кемеровской области (населенные пункты г. Новокузнецк, г. Осинники, г. Калтан), в вышеупомянутой Иркутской области указали на ряд проблем, а также на неурегулированных земельным, градостроительным законодательством вопросов, осложняющих процесс оказания помощи населению, защите населения и территорий от проявления подобных ЧС. Например, отсутствие зарегистрированных прав собственности или утрате в результате ЧС правоустанавливающих документов, затрудняет или делает невозможным процесс признания жилых помещений непригодными для проживания, восстановления утраченного имущества, оценки нанесённого ущерба муниципальному образованию в целом.

Все эти факторы в совокупности обосновали необходимость совершенствования механизма защиты территорий и объектов недвижимости от негативного влияния вод с проведением комплекса кадастровых, землеустроительных и инвентаризационных работ. По поручению Президента в 2017 году Правительству, совместно с органами МЧС и органами государственной власти субъектов РФ необходимо в кратчайшие сроки принять меры по реализации противопаводковых мероприятий, защиты населения от ЧС [9].

Исходя из анализа содержания Водного кодекса, защитить население и объекты, инфраструктуры, недвижимости от затоплений, подтоплений возможно:

- путем строительства инженерной защиты на освоенных территориях, в предполагаемых зонах ЧС, связанных с наводнениями и подтоплениями;

- запрета возведения новых объектов на паводко-опасных участках.

Таким образом, возникает главная задача - определить границы зон затопления, подтопления (границы 33, ЗП). 
В 2014 вступает в силу Постановление Правительства, устанавливающее правила определения границ зон затопления, подтопления, которое в последствие дважды претерпевает изменения: в 2016, после исключения зон затопления, подтопления из объектов землеустройства и отнесения их к ЗОУИТ и в 2019 году, в части контроля выполнения работ и их сроков. Принципиальным отличием действующей редакции № 3 от Постановления от редакции № 2 от 17.05.2016 г. является [10]:

- включение территориального управления Росреестра, как согласующего органа при установлении границ 33 и ЗП для водных объектов;

- установление пятидневного срока для направления сведений в ГВР и ЕГРН, уведомления органов местного самоуправления о принятие решения об установления границ 33 и ЗП для водных объектов, МЧС о внесении сведений в ЕГРН;

- требования к территориям, входящих в границы 33 и ЗП.

Порядок установления границ 33, ЗП показан на рисунке 3. Согласно постановлению, 33, ЗП могут быть установлены или изменены решением Федерального агентства водных ресурсов на основании предложений Министерств природных ресурсов субъекта РФ и органа местного самоуправления и сведений, содержащих графическое описание местоположения границ, этих зон, перечень координат характерных точек границ [10].

\begin{tabular}{|c|c|c|c|c|c|}
\hline \multirow{7}{*}{ 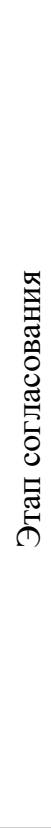 } & \multicolumn{2}{|c|}{$\begin{array}{c}\text { Предложения Минприроды } \\
\text { НСО и Мэрия г. Новосибир- } \\
\text { ска }\end{array}$} & \multirow{7}{*}{ فำ } & \multirow{3}{*}{\multicolumn{2}{|c|}{$\begin{array}{c}\text { Утверждает Верхне-Обское БВУ } \\
\text { В течении } 5 \text { дней уведомляет Мэрию г. Новосибирска }\end{array}$}} \\
\hline & \multicolumn{2}{|c|}{ Согласующие органы } & & & \\
\hline & $\begin{array}{c}\text { ГУ МЧС по } \\
\text { НСО }\end{array}$ & \multirow{2}{*}{$\begin{array}{c}\text { Управление } \\
\text { Росреестра } \\
\text { по НСО }\end{array}$} & & & \\
\hline & & & & \multirow{3}{*}{\multicolumn{2}{|c|}{$\begin{array}{c}\text { Считаются установленными со дня внесения сведений в } \\
\text { ЕГРН. } \\
\text { В течении } 5 \text { дней после получения уведомления о внесении } \\
\text { сведений в ЕГРН Верхне-Обское БВУ } \\
\text { уведомляет }\end{array}$}} \\
\hline & $\begin{array}{l}\text { Сибирское м } \\
\text { управление }\end{array}$ & $\begin{array}{l}\text { егиональное } \\
\text { природнад- }\end{array}$ & & & \\
\hline & \multicolumn{2}{|c|}{$\begin{array}{l}\text { Департамент Росгидромета } \\
\text { по СФО (зоны затопления) }\end{array}$} & & & \\
\hline & \multicolumn{2}{|c|}{$\begin{array}{c}\text { Департамент Роснедра по } \\
\text { СФО }\end{array}$} & & ГУ МЧС по НСО & МЧС РФ \\
\hline
\end{tabular}

Рис. 2. Порядок установления границ 33, ЗП на примере НСО

Открытым остается вопрос о порядке изменения или прекращении существовании 33, ЗП. В Постановление говорится о том, что зоны могут прекратить свое существование лишь одновременно с прекращением существования водного объекта. Граница зоны может быть изменена только в результате: 
- возникновение аварий или иных ЧС, в результате прохождения паводка $1 \%$ обеспеченности (1 раз в 100 лет);

- сложной ледовой обстановки, пропуска вод в катастрофически большом количестве, не реже 1 раза в 10 лет.

- внесение изменений в документы территориального планирования, градостроительного зонирования и документацию по планировке территорий.

При этом отсутствует возможность корректировать границу 33, ЗП при искусственном изменении русла и дна водных объектов, строительстве объектов инженерной защиты территорий. Это значит, что территории, обеспеченные инженерной защитой, также будут находиться в зоне затопления, подтопления.

Постановление Правительства РФ существенно ограничивает территории, в отношении которых допустимо определять границы зон затопления и подтопления. Новая редакция Постановления внесла изменения в Требования к территориям, входящим в границы 33, ЗП. Ранее в пункте 1 а) на не зарегулированных водотоках (на реках, ручьях, каналах на которых отсутствуют гидроузлы или отдельные ГТС, регулирующие естественный сток) выделялись зоны, затапливаемые в результате ледовых заторов и зажоров, а также зоны, затапливаемые при паводках повторяемостью раз в 1, 3, 5, 10, 25 и 50 лет. Теперь на таких водотоках определяются зоны при половодьях и паводках только однопроцентной обеспеченности, то есть повторяемостью 1 раз в 100 лет. Поэтому приобретая имущество, возведенное до установления границ 33, ЗП вблизи водных объектов без инженерной защиты от наводнений и паводков нельзя в полой мере оценить риски утраты и возможность компенсации в результате частичного или полного разрушения объекта недвижимости [10].

Пункт 1 д) указывает на необходимость определять границы 33, ЗП для территорий нижних бьефов гидроузлов при пропуске паводков расчетной обеспеченности гидроузла. Например, г. Новосибирск находится в нижнем бьефе Новосибирского гидроузла. Новосибирский гидроузел состоит из Новосибирского водохранилища, здания ГЭС, плотины ГЭС и судоходного шлюза, имеет 1 класс опасности (ГТС чрезвычайно высокой опасности). Расчетная обеспеченность гидроузла $0,01 \%$, согласно техническому проекту и «Правил эксплуатации водохранилища Новосибирской ГЭС». Это значит, что он способен пропустить паводок в таком объеме, который повторяется 1 раз в 10 тыс. лет. Определить объем пропуска и уровень воды при таком паводке крайне трудно, расчёты основываются на математической модели максимальных паводков за историю наблюдения. Например, для Новосибирского водохранилища по моделям весеннего половодья 1937 и 1969 годов. Согласно проектным и расчетным характеристикам при паводке 0,01 \% пропускная способность Новосибирского гидроузла через турбины ГЭС, водосливную плотину холостых сбросов, донные водосбросы и шлюзовой канал составит около 23 тыс. $\mathrm{m}^{3} / \mathrm{c}$, при среднем ежегодном расходе $2000 \mathrm{~m}^{3} / \mathrm{c}$, и максимальном за последние 6 лет $6246 \mathrm{~m}^{3} / \mathrm{c}$, при притоке $7500 \mathrm{~m}^{3} / \mathrm{c}$ (паводок $50 \%$ обеспеченности, повторяемостью 1 раз в 50 лет, 2015 г.). При уровне воды в реке Обь 350-380 см и объеме сброса около $3800 \mathrm{~m}^{3} / \mathrm{c}$ начинается 
затопление садовых товариществ Первомайского района: СНТ «Геолог», СНТ «Геофизик», СНТ «Дорожник», СНТ «Театральный», отображены на рис. 3 [11].
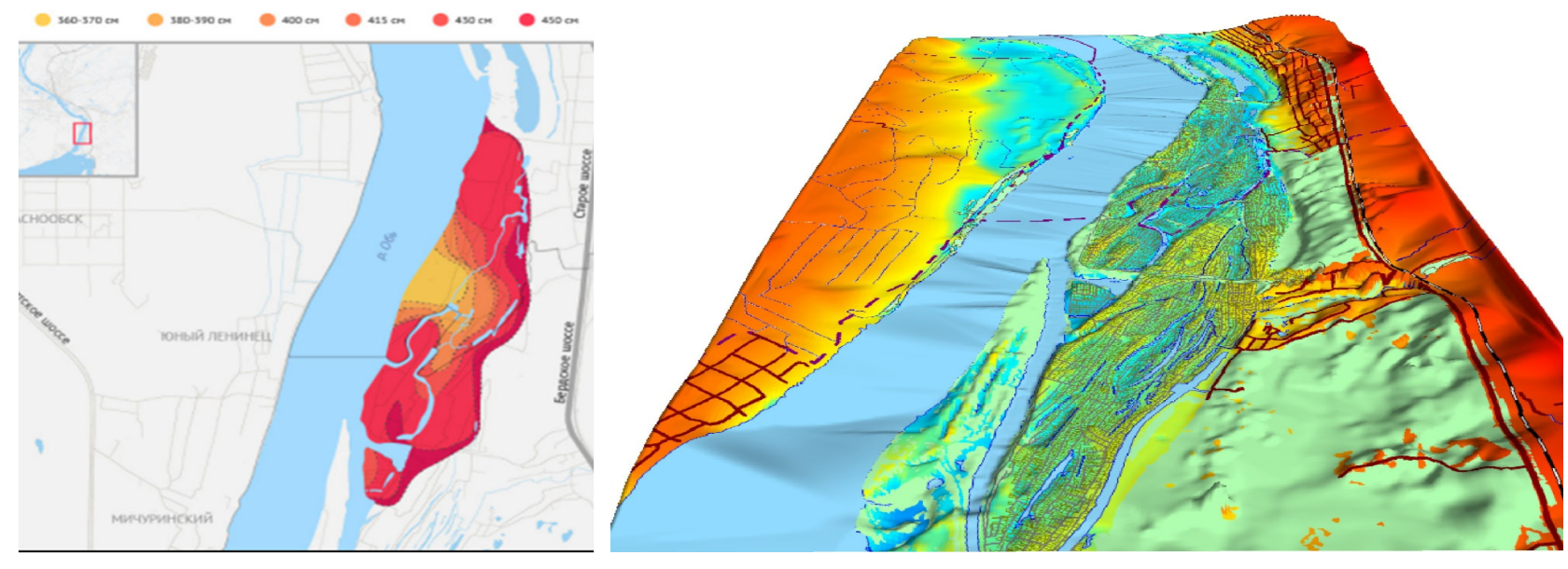

Рис. 3. Границы 33 и ЗП г. Новосибирска при сезонном паводке (на рисунке справа показана объемная модель территории, попадающей в 33 и ЗП)

Затруднительно объяснить целесообразность определения такой границы, так как под ограничения использования объектов недвижимости и хозяйственной деятельности будут попадать огромные территории. При этом ограничения для всех территорий, попадающих в зоны затопления при разной обеспеченности паводков одинаковы. Очевидно, что для каждой зоны затопления необходимо вводить разные виды ограничений, основываясь на особенностях прохождения паводков и характеристик самих территорий и водного объекта. Кроме того, обеспечить инженерной защитой территорию, подверженную катастрофическому паводку, проходящему 1 раз в 10 тыс. лет, крайне сложно, а порой это является не решаемой инженерной и строительной задачей [12]. К тому же данное требование защитить территорию от паводка 0,01 \% противоречит своду правил «Градостроительство. Планировка и застройка городских территорий», которая указывает на необходимость строительства инженерной защиты застроенных или подлежащих застройке территорий от паводка 1\% обеспеченности, повторяемостью 1 раз в 100 лет [12]. В 2020 г. такая зона затопления и прилегающая к ней зона подтопления были утверждены и внесены в ЕГРН, что послужило требованиям правообладателей недвижимости в их границах защитить территории от негативного влияния вод или пересмотреть размеры установленных границ зон.

С подобными требованиями с 2017 года в суды общей юрисдикции обращались жители Алтайского края, которым отказано в выдаче разрешений на строительство индивидуальных жилых домов на участках, принадлежащих им на праве собственности до того, как в отношении таких участков были установлены границы 33, ЗП [13]. 
Определение границ 33 для нижних бьефов гидроузлов, особенно таких крупных как Новосибирский гидроузел, имеющий чрезвычайно высокий класс опасности, не может основываться только на нормах, указанных в Постановлении [10]. Если рассматривать г. Новосибирск, то сложность определения территорий, попадающих в 33, ЗП заключается в том, что ниже плотины ГЭС находятся и другие водные объекты, которые впадают в р. Обь, могут осложнить прохождение паводка или наоборот, высокий уровень воды в р. Обь может вызвать подъем уровня воды в водных объектах (не только притоков 1 порядка) и привести к затоплению и подтоплению территорий. Руководствуясь нормами Постановления невозможно учесть влияние водных объектов друг на друга при различной гидрометеорологической обстановке и не имеющих гидравлической связи. В результате в ЕГРН вносятся сведения в не полном объеме, что может являться причиной разрешения строительства объектов недвижимости на потенциально-опасных территориях [14].

Кроме того, Постановление Правительства предусматривает определение границ зон подтопления, прилегающих к зоне затопления. Предусматривается определение границ только на тех территориях, где подтопления вызваны высоким уровнем вод в поверхностном водном объекте и поднятием уровня грунтовых вод. Определение территорий, с отрицательными формами рельефа, близким расположением к поверхности подземных водных объектов (водоносных горизонтов, бассейнов подземных вод, месторождений подземных вод) не предусматривается. При этом не существует никаких других документов, указывающих на необходимость и регламентирующих порядок определения таких зон. Такие территории останутся не определёнными и не изученными, а объекты недвижимости и инфраструктуры не защищены, пока не будут внесены соответствующие изменения в требования к территориям, входящим в 33, 3П [10].

В настоящее время определен перечень ограничений, одинаковых как для зон затопления, так и для зон подтопления. При этом характер воздействия вод на здания, строения, сооружения при затоплении и подтопление грунтовыми водами разный. По этой причине необходимо разработать и нормативно закрепить разные виды запретов, касающихся ведения хозяйственной деятельности на таких территориях [1].

Для того, чтобы в полном объеме определить территории муниципальных образований, подверженных затоплению, подтоплению и внести сведения в ЕГРН необходимо пересмотреть требования к территориям в отношении которых определяются границы 33, ЗП [14]. Определить границы зон затопления и подтопления для искусственно регулируемых водных объектов невозможно основываясь на сведениях об отметках высот территорий и сведениях о расходах и уровня воды при разной обеспеченности паводка. Необходимо создание гидродинамической модели, которая будет учитывать и различные условия которые оказывают влияние на характер и размеры затопления территорий, например, этими факторами могут быть: плотность застройки территорий, количество и места установки мостовых сооружений, характеристика подземных водных объектов, тип и свойства грунтов и слагающих пород, другие водные объекты. 
Подводя итоги, можно сделать выводы о том, что определение границ 33, ЗП позволяет:

- осуществлять эффективное планирование территорий с учетом рисков возникновения ЧС;

- обосновать необходимость строительства гидротехнических объектов и обеспечить территории инженерной защитой от затоплений, подтоплений;

- в короткие сроки оказывать помощь населению, имущество которого полностью или частично разрушены, при утрате правоустанавливающих документов в результате ЧС;

- на основании сведений ЕГРН об объектах, попадающих в 33, ЗП оценивать масштабы ущерба, для планирования бюджета на осуществление мероприятий по ликвидации последствий ЧС;

- определять размер страхового платежа и сумму страхования для имущества, с учетом рисков утраты или повреждения имущества в результате негативного влияния вод.

\section{БИБЛИОГРАФИЧЕСКИЙ СПИСОК}

1. Водный кодекс Российской Федерации от 03.06.206 № 74 - Ф3 (ред. От 31.10. 2016). Доступ из справ.-правовой системы «КонсультантПлюс».

2. Указ Губернатора Иркутской области от 27.06.2019 № 134-уг "О введении режима чрезвычайной ситуации на территории Иркутской области". [Электронный ресурс] - режим доступа: http://publication.pravo.gov.ru/Document/View/3800201906270010. - Заг. с экрана.

3. Сводка оперативной информации Персс-центра ГУ МЧС по Иркутской области на 06.00 (НСК) 28.06.2020. Сайт Главного Управления МЧС России по Иркутской области [Электронный ресурс] - режим доступа: https://38.mchs.gov.ru/deyatelnost/press-centr/operativnayainformaciya/svodka-chs-i-proisshestviy/4193981. - Заг. с экрана.

4. Об утверждении Программы по восстановлению жилья, объектов связи, социальной, коммунальной, энергетической и транспортной инфраструктур, гидротехнических сооружений, административных зданий, поврежденных или утраченных в результате наводнения на территории Иркутской области. Распоряжение Правительства Российской Федерации от 18 сентября 2019 года N 2126-р. [Электронный ресурс] - режим доступа: http://enbvu.ru/i03_deyatelnost/i03.19_chs_Irkutskaya_oblast.php. - Заг. с экрана.

5. Градостроительный кодекс Российской Федерации от 29.12.2004, № 190-Ф3 (ред. от 31.07.2020) (с изм. и доп., вступ. в силу с 28.08.2020) - Доступ из справ. -правовой системы «КонсультантПлюс».

6. Нормативно-правовые особенности установления водоохранных зон и прибрежных защитных полос (На примере территорий Новосибирской области) / В. А. Бударова, Е. А. Воронина, А. В. Дубровский, И. Н. Кустышева, О. И. Малыгина, Н. Г. Мартынова, О. Ф. Торсунова// Вестник СГУГиТ, Том 24, № 1, 2020. - СГУГиТ, 2020. - С. 222-238.

7. РБК. Недвижимость. [Электронный ресурс]- режим доступа: https://realty.rbc.ru/news/5eba7c799a79475b7abbe540?utm_source=yxnews\&utm_medium=desktop. Заг. с экрана.

8. О безопасности гидротехнических сооружений. Федеральный закон от 21.07.1997 № 117-Ф3 (ред. от 29.07.2018). - Доступ из справ. -правовой системы «КонсультантПлюс».

9. Перечень поручений по итогам совещания по ликвидации последствий паводков и пожаров от 15.05.2017. [Электронный ресурс] - режим доступа: http://www.kremlin.ru/acts/assignments/orders/54579. - Заг. с экрана. 
10. О зонах затопления, подтопления (вместе с Положением о зонах затопления, подтопления). Постановление Правительства РФ от 18.04.2014 № 360 (ред. от 07.09.2019). Доступ из справ. -правовой системы «КонсультантПлюс».

11. 11.Графики установления режимов работы Новосибирского водохранилища. [Электронный pecypc]режим доступа:

$\mathrm{http}: / /$ vobvunsk.ru/index.php?option=com_content\&view=article\&id=1217\&Itemid=66.

12. СП 42.13330.2016. Свод правил. Градостроительство. Актуализированная редакция СНиП 2.07.01-89. Доступ из справ. -правовой системы «КонсультантПлюс».

13. Решение № 2А-598/2017 2А-598/2017 М-487/2017 М-487/2017 от 29 декабря 2017 г. по делу № 2A-598/2017 [Электронный ресурс] - режим доступа: https://sudact.ru/regular/doc/CQwP1T6C7hHZ/. - Заг. с экрана.

14. Клюшниченко, В. Н., Москвин, В. Н., Татаренко В. И. К вопросу о ведении Единого государственного реестра недвижимости в России // Вестник СГУГиТ, Том 23, № 3, 2018. - СГУГиТ, 2018. - С. 240-248.

15. Карпик А.П. Анализ природных и техногенных особенностей геопространства чрезвычайной ситуации [Текст] / А.П. Карпик, Э.Л. Ким, А.В. Дубровский. - Итерэкспо ГЕО-Сибирь-2012. VIII Междунар. науч. конгр., 10-20 апреля 2012 г., Новосибирск: Междунар. науч. конф. «Геодезия, геоинформатика, картография, маркшейдерия»: сб. материалов в 3 т. Т.3. Новосибирск: СГГА, 2012. С. 171-177.

16. Каганович А.А. Планирование территориальной устойчивости с использованием геоинформационных систем. Известия Санкт-Петербургского государственного аграрного университета 1 (46), 2017 г. СПб.: Санкт-Петербургский государственный аграрный университет, 2017. С. $203-207$.

17. Дубровский, А. В. Разработка проекта водоохранной зоны на территорию Новосибирского водохранилища [Текст] / А. В. Дубровский, Е. А. Воронина. - Интерэкспо ГЕОСибирь. XIV Междунар. науч. конгр., 23-27 апреля 2018 г., Новосибирск : Междунар. науч.-технолог. конф. студентов и молодых ученых «Молодежь. Наука. Технологии» : сб. материалов в 2 т. Т. 1. - Новосибирск : СГУГиТ, 2018. - С. 82-87.

18. О внесении изменений в отдельные законодательные акты Российской Федерации. Федеральный закон от 03.08.2018 № 320-Ф3 - Режим доступа: http://publication.pravo.gov.ru/Document/View/0001201808030083?index=0\&rangeSize=1.

(C) А. В. Дубровский, Е. А. Скоринская, 2021 